\title{
Aluminum Lactate
}

National Cancer Institute

\section{Source}

National Cancer Institute. Aluminum Lactate. NCI Thesaurus. Code C78772.

A topical astringent that is used as an antiseptic agent. Aluminum lactate is used to treat inflammation, itching, and sting ing of the infected skin and promotes healing. 